\title{
Comparison of Legal System of Occupational Safety and Health between Hong Kong and Mainland China
}

\author{
Qiang Chen ${ }^{1}$, Yin-Ge Cao ${ }^{1}$, Wan-Ki Chow ${ }^{2 *}$ \\ ${ }^{1}$ College of Safety and Environment, Capital University of Economics and Business, Beijing, China \\ ${ }^{2}$ Research Centre for Fire Engineering, Department of Building Services Engineering, The Hong Kong Polytechnic University, \\ Hong Kong, China \\ Email: "beelize@polyu.edu.hk
}

Received December 28, 2011; revised February 3, 2012; accepted February 21, 2012

\begin{abstract}
The legal system of occupational safety and health (OSH) and the supervisory organization in Mainland China and Hong Kong are briefly reviewed in this article. It appears that there are several similar areas of OSH between Hong Kong and Mainland China, such as on the management of occupational health, safety production, fire safety, dangerous goods, the boilers and pressure vessels, etc. Characteristics of the legal system both in Hong Kong and Mainland China are summarized, and areas which are used for reference reciprocally to improve OSH are proposed. Finally, the challenges of OSH legal system facing jointly are identified.
\end{abstract}

Keywords: Occupational Safety and Health; Supervisory Organization; Legal System; Areas for Improvement

\section{Introduction}

Practices of Occupational Safety and Health (OSH) management are a good indication on development of economics of the urban area to some extent. With the quick development of economics in China, professionals in all disciplines have paid more notice on OSH. Now, OSH is not only watched carefully by Authority Having Jurisdiction (AHJ). In recent years, health and safety at work is taken as an important subject by all employers and employees in enterprises. In addition to prescriptive regulations which might not be applicable for new subject disciplines, a broad knowledge is required in safety engineering, industrial hygiene and medicine, ergonomics, and psychology. Through the development for many years, progress of the OSH regulatory system in China is expanding gradually. It is carried out and implemented in the society as a fundamental requirement. Hong Kong is a special administrative region of China. There are some similarities and cross-cultural differences between the two regions on OSH. It is interesting to review the current situation on OSH in Mainland China and Hong Kong to give more insight into the present status of supervisory organization, legal system and the major legislations concerned and to share the advantages of both sides with the aim of promoting the development of OSH together.

${ }^{*}$ Corresponding author.

\section{Introduction of OSH Legal System in Mainland China}

\subsection{Supervisory Organization}

There are three major supervisory organizations on OSH in China as the State Administration of Work Safety of the People's Republic of China (SAWS) [1], General Administration of Quality Supervision, Inspection and Quarantine of the People's Republic of China (AQSIQ) [2], and the Ministry of Health of the People's Republic of China (MHPRC) [3].

The SAWS and local administrations of work safety are responsible for main administrative and executive functions of OSH in Mainland China. There are four supervision departments under SAWS with responsibilities for supervising and managing safety in production of different industries. A new department, supervision department on occupational safety and health, was set up in 2008. It takes care of the following aspects on occupational health: supervision and inspection of the status on occupational health for industrial and trade business (except for coal mine workplaces); drafting of enforcement regulations and standards of occupational health in workplaces; organization of investigation and dealing with occupational health accidents and the offensive practice; undertaking the awarding management of the safe licenses of the occupational hygiene; organization of guiding and inspection of education and training as to occupational health; organization of guiding the busi- 
nesses and operations to declare of the occupationaldisease hazardous; and participation in emergency response operations and rescue of occupational health accidents. Other departments under SAWS include the Office of Work Safety Emergency (Statistics Department), Department of Policy and Regulation, Department of Planning, Science and Technology, etc.

State Administration of Coal Mine Safety is an administration of vice-ministerial level under SAWS which undertakes the responsibility of supervision on coal mines, and inspection of the administrative work of local government [4].

Supervision Administration of Special Equipment, the subsidiary department of AQSIQ, which is the government under the State Council, takes charge of the administration of special equipment $[5,6]$.

The MHPRC also takes charge of several administrative and executive functions of occupational safety and health, which includes [7]: legislate laws and standards on occupational health; supervise the implementation of relevant legislations; supervise and administer national occupational diseases prevention; examine and approve the construction project on occupational health; and approve administrative license qualification (Grade A) of occupational-health technical service organizations.

\subsection{The Legal System Framework on OSH}

Based on the Constitution of the People's Republic of China, the legal system framework of OSH is consisted of laws system, standards system and international treaties. The framework chart of legal system of $\mathrm{OSH}$ is shown in Figure 1.

There are five branches of the laws system as:

- Laws, adopted by the National People's Congress of the People's Republic of China or its Standing Committee [8-10], promulgated and shall be effective by President of the People's Republic of China.

- Administrative Law adopted and promulgated by the State Council [11,12].

- Local Law adopted and promulgated by provincial government.

- Regulations adopted and promulgated by ministries and commissions and government.

- Autonomy ordinance and single ordinance adopted and promulgated by the government of autonomous region.

Laws related to OSH include special laws and relevant laws. Special laws on safety at work include: Production Safety Law of the People's Republic of China, which is the basic law on safety at work; Fire Prevention Law of the People's Republic of China; Law of the People's Republic of China on Road Traffic Safety; Maritime Traffic Safety Law of the People's Republic of China; Law of the People's Republic of China on Safety in Mines; The Law of the People's Republic of China on Emergency Responses, etc. The basic special law related to occupational health is Code of Occupational Disease Prevention of PRC. Relevant laws refer to laws containing provisions as to occupational safety and health and that apart from the special laws, such as Labour Law of the People's Republic of China, Trade Union Law of the People's Republic of China, Railway Law of the People's Republic of China, Construction Law of the People's Republic of China. Relevant laws also refer to laws related to supervision and enforcement of safety production, for instance, Criminal Law of the People's Republic of China, Law of the People's Republic of China on Administrative Penalty.

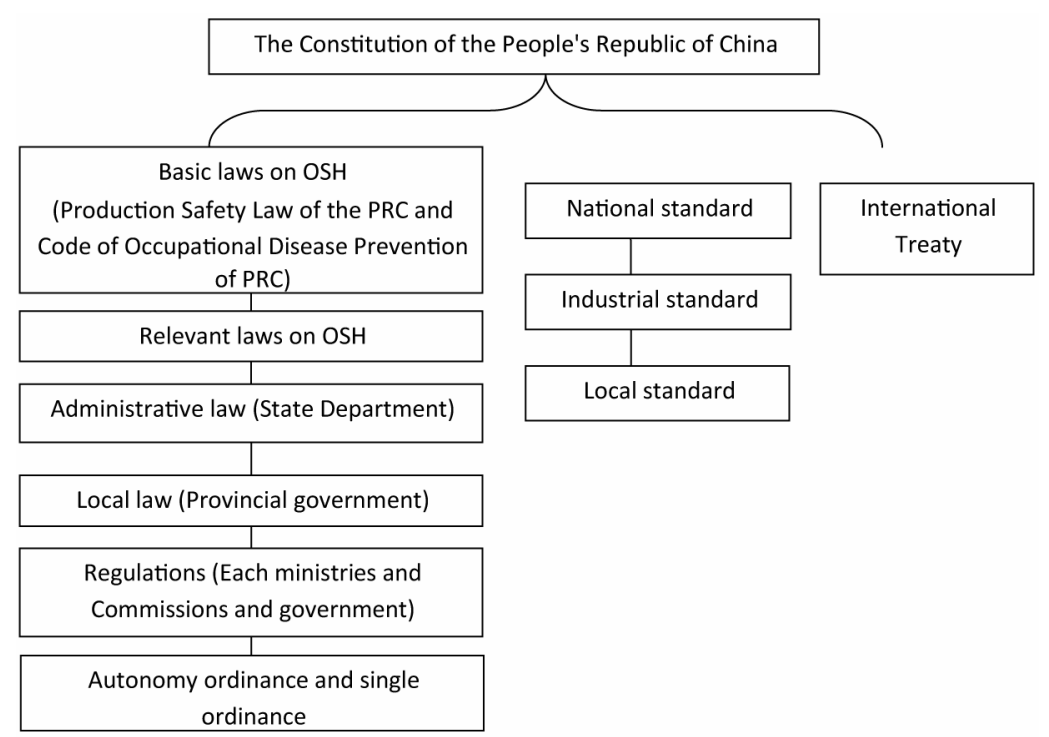

Figure 1. Framework chart of legal system of OSH in Mainland China. 
The major administrative laws of occupational safety and health include Regulation on Work Safety Management of Construction, Regulations on the Control over Safety of Dangerous Chemicals, Coal Mine Safety Supervision Regulation, Regulation on Work Safety Licenses, Regulations on Safety Supervision over Special Equipment, Regulations Concerning the Labor Protection of Female Staff and Workers, Work-related Injury Insurance Regulations, etc.

The standards system includes national standards, industrial standards and local standards, which is with more strict provisions than national standards. The major national standards of occupational safety and health include: Classification and code for the hazardous and harmful factors in production process $\left(\mathrm{GB} / \mathrm{T}^{1} 13861-92\right)$, Identification of major hazard installations $\left(\mathrm{GB}^{2} 18218-\right.$ 2000), Classification standard for the casualty accidents of enterprise staff and workers (GB 6441-86), Rule for storage of chemical dangers (GB 15603-1995), Classification and labels of dangerous chemical substances commonly used (GB 13690-92), Design code for protection of structures against lightning (GB 50057-1994), Hygienic standards for the design of industrial enterprises $\left(\mathrm{GBZ}^{3}\right.$ 1-2002), Occupational exposure limits for hazardous agents in the workplace Part 1: Chemical hazardous agents (GBZ 2.1-2007), Occupational exposure limits for hazardous agents in the workplace Part 2: Physical agents (GBZ 2.2-2007), Classification of health hazard levels from occupational exposure to toxic substances (GB 5044-85), Classified standard of operation with exposure to toxic chemicals in the workplace (GB 1233190), Classification of hazard levels due to exposure to industrial dust (GB 5817-86), Classification of works in heat environment (GB/T 4200-1997), Classification of works in cold environment (GB 3869-1997), Classification on intensity of physical work (GB 3869-1997), Classification of works in cold water (GB/T 14439-93), etc.

The main List of Treaties in force and International Agreements applicable to Mainland China related to occupational safety and health include Convention on Safety in the use of Chemicals at work (ILO No. 170), Convention on Occupational Safety and Health (ILO No. 155), Occupational Health Services Convention (ILO No. 161), etc.

\subsection{Legal Liability}

Under Production Safety Law of the People's Republic of China, the major persons-in-charge of the production and business operation entities shall have the following duties and responsibilities regarding the production safety of their own entity: 1) Establishing and perfecting the

\footnotetext{
${ }^{1} \mathrm{~GB} / \mathrm{T}$ - Recommendatory national standard.

${ }^{2} \mathrm{~GB}$-National standard.

${ }^{3} \mathrm{GBZ}$-National standard on occupational health.
}

system of responsibility relating to production safety; 2) Organizing the formulation of rules of safe production and operational rules of the entity; 3) Ensuring the effective execution of input in production safety; 4) Overseeing and inspecting the work of production safety of the entity and eliminating in good time the potential production safety accidents; 5) Organizing the formulation and execution of plans for emergency rescue and relief of production safety accidents of the entity; and 6) Reporting production safety accidents truthfully and in good time.

The production and business operation entities shall: have archivist files for substantial hazardous, make regular checks, appraisals, supervisions and controls, make emergency plans; provide education and training programs concerned about occupational health and safety at work to the employees; and maintain the safety facilities often and check them regularly to ensure normal operation. Records shall be made for the services, to which the signature of relevant persons shall be affixed. The production and business operation entities shall also take effective measures and have good understanding of the safety and technical feature for safety production, where any new technique, new technology, new material or new equipment is adopted; provide personal protective equipment that meet the national standards or industrial standards to the employees; supervise and educate them to wear or use these articles according to the prescribed rules, and effect the policy covering the work-related injuries according to applicable laws.

The employer shall take the following measures for prevention and management of occupational diseases: to provide for the occupational-disease-prevention plan and the enforcement plan; to establish/improve the occupational health management system and operating rules; to establish/maintain occupational health archives and laborer health records; to establish/improve the system for supervision and assessment of the workplace occupational-disease-inductive factors; and to establish/improve contingency plan for occupational-disease-inductive accidents.

The employees of a production and business operation entity, under Production Safety Law of the People's Republic of China, shall be entitled to know the dangerous elements that exist in the site or position of work as well as the corresponding prevention measures and emergency measures; to give suggestions concerning the work of production safety of the entity where they work; to criticize, expose or institute legal proceedings on the ground of the problems that exist in the production safety of the entity concerned; to refuse to give directions as against the operational rules or to force people to work in risks; and to stop work or leave the site of work after taking possible emergency measures, where any employee finds any emergency that may directly endanger 
the personal safety of him or any other person.

Meanwhile, the laborer shall rigidly observe the rules and regulations concerning production safety and the operational rules of the entities concerned, obey their administration, and correctly wear and use personal protective equipment; accept education and training in production safety, be equipped with the knowledge of production safety necessary for their work so as to improve their skills in production safety and enable themselves to prevent from accidents and handle emergencies. Any employee who finds out any potential accidents or other insecure elements shall report immediately to the person in charge of the on-spot administration of production safety or the person-in-charge of the entity concerned. The person who receives the report shall handle them in good time.

The laborers, under Code of Occupational Disease Prevention of PRC, are entitled to the following occupational-health-protection rights: The opportunity of occupational health education and training; Occupationaldisease-prevention services like occupational health examination, occupational disease diagnosis and rehabilitation; Understand the actual (or possible) occupationaldisease-inductive factors, their harmful effect and necessary occupational-disease-prevention measures in the workplace; Ask the Employer to provide the occupational-disease-prevention equipment and individual-used occupational-disease-prevention articles to improve the working conditions; Criticize, impeach and accuse the practices that violate occupational-disease-prevention laws and regulations and harm human health; Deny the illegal orders and commands to undertake the operation without the safeguard of occupational-disease-prevention measures; and participate in the democratic management of the Employer's occupational health work, and bring forward comments and suggestions with regard to the occupational-disease-prevention operation.

A department responsible for the supervision and administration of production safety supervise and inspect according to law the executions of the relevant laws and regulations concerning production safety and the national or industrial standards by the production and business operation entities, and shall have the following duties and functions by the provisions of Production Safety Law of the People's Republic of China: 1) to make inspections at the production and business operation entities, gather relevant materials, and inquire relevant entities and persons; 2 ) to correct the acts violating the statutory provisions of law and discovered in the inspections or demand for correction within a prescribed time limit; to make decisions of administrative penalties according to the provisions of the present law and other relevant laws and regulations to those acts that shall be subject to administrative penalties according to law; 3 ) if it finds any po- tential accident in its inspections, it shall order them to be eliminated without delay. If safety cannot be guaranteed before a serious potential accident is eliminated or in the process of elimination, it shall order the employees at work to leave the dangerous areas, and order that the business operation or production or use be suspended or terminated. The production or business operation or use may not be resumed until the serious potential accident has been eliminated and approval has been obtained upon examination; 4) shall be entitled to seal up or detain the facilities, equipments and apparatuses that are believed as not meeting the national or industrial standards for guaranteeing production safety. The supervision and inspection may not affect the normal production and business operation activities of the examinee entities.

In addition, the key industries should establish OSH management agencies or departments, for example, under Production Safety Law of the People's Republic of China, the mines entities, construction entities and those engaged in the production, selling and storage of hazardous substances, as well as the other production and business operation entities that have more than 300 employees, shall establish an administrative organization for production safety or have full-time personnel for the administration of production safety. If the production and business operation entities, without high-risk, that have fewer than 300 employees, they shall have full-time or part-time personnel for the administration of production safety or entrust the engineering technicians who are equipped with the relevant professional technical qualifications as provided by the state to provide services in the administration of production safety. Meanwhile, under Code of Occupational Disease Prevention of PRC, the employer shall set up or appoint the occupational health management organizations or agencies staffed with fulltime or part-time medical professionals for the in-house occupational disease prevention.

\subsection{Hazards Identification and Management}

There are three major laws and national standards making provisions for management of hazard. These are Production Safety Law of the People's Republic of China, Identification of Major Hazard Installations (GB 182182000), and Classification and Code for the Hazardous and Harmful Factors in Production Process (GB/T 1386192).

Under Production Safety Law of the People's Republic of China, production and business operation entities shall have archivist files for substantial hazardous sources, make regular checks, appraisals, supervisions and controls, make emergency plans, and inform the employees and other relevant people of the emergency measures that should be taken under emergent circumstances. They shall report, according to the relevant provisions of the 
state, the substantial hazardous and the corresponding safety measures and emergency measures to the administrative department and other relevant departments of the local people's government in charge of the supervision and administration of production safety for archivist purposes.

The national standard Identification of Major Hazard Installations (GB 18218-2000) makes the provisions of the method to identify major hazard installations. Under this standard, the major hazard installations refers to the hazardous substance which are produced, processed, carried, used or stored long-term or temporarily and the quantity of the dangerous substance means or exceeds the unit of threshold quantity. It is based on the characteristics and quantity of the risk to identify the major hazard. The major hazard installations are divided into two types: major hazard installations on work site and that on store area. The threshold quantity is provided according to four types of dangerous characteristics as follows: volatile, inflammable, active and poisonous.

Another reference standard to identify hazards which is used widely in industries is the national standard Classification and Code for the Hazardous and Harmful Factors in Production Process (GB/T 13861-92). It divides the hazardous and harmful factors into six types as follows: physical agents, chemical agents, biological agents, behavior agents, psychosocial agents, and other agents.

\subsection{OSH Assessments, Qualifications and Certificate}

\subsubsection{The “Three Simultaneity" Management of Construction Projects}

Under Production Safety Law of the People's Republic of China, Code of Occupational Disease Prevention of PRC, the safety facilities of the newly built or rebuilt or expanded engineering projects of the production and business operation entities shall be designed, built and put into production and use at the same time of the principal part of the projects and the investment in safety and occupational disease prevention facilities shall be incorporated in the budgetary estimates of the construction projects concerned.

\subsubsection{Safety Assessments and Occupational Hazard Assessment}

1) Safety Assessment

Under Production Safety Law of the People's Republic of China, safety conditions argumentations and safety assessment shall be made according to the relevant provisions of the state to the mining construction projects and the construction projects for the production and storage of hazardous substances respectively. After a mining construction project or a construction project for the production and storage of hazardous substances is completed and before it is put into production or put into use, the safety facilities shall be subject to check and approval according to the relevant provisions of laws and administrative regulations.

Safety assessment, in accordance with the different stages of implementation, has been divided into three categories: general rules of safety evaluation, safety assessment prior to start, safety assessment upon completion, and safety assessment in operation. The rules specify the grounds, objectives, requirements, procedures and techniques for safety assessment. A safety assessment report will include details such as the identification of risks, the level and reasons of risks, the potential dangers to the production and people and the appropriate safety procedures to be adopted.

- Safety assessment prior to start refers to the activities be taken in the feasibility study phase, the planning phase of industrial park or before the operation that identifies and analyzes risks according to the basic materials of production; to ensure that the hazards identified comply with relevant laws, standards and legal requirements; predict the possibility and severity of the potential accident; advise precautions which is scientific, reasonable, and feasible; and make conclusions.

- Safety assessment upon completion refers to the activities be taken after a construction project is completed and before it is put into production or put into use: to check the whether the construction projects comply with the requirement of "Three simultaneity"; to check the using status of the safety facilities, equipments and devices; to check the implementation of safety measures; to inspect the adequacy of safety operation regulations; to inspect the establishment of emergency plan and procedures; to censor whether the construction projects comply with relevant laws, standards, legal requirements; and make conclusions.

- Safety assessment in operation refers to the activities that aim at the activities of production, the accident risk of industrial park, and the management of safety; identify and analyze of risks; predict the possibility and severity of the potential accident, advise precautions which is scientific, reasonable, and feasible; and make conclusions.

The safety assessment in operation is suitable not only for a production and business operation entity or an industrial park, but also suitable for a certain particular mode of production, production technical production device or workplace.

2) Occupational Hazard Assessment of Construction Projects

Under Code of Occupational Disease Prevention of PRC: for any new, expansion or modification projects, technical modification projects and technology introduc- 
tion projects (referred to as "Construction Projects") that have high occupational disease exposure, the responsible organizations should, in the feasibility study phase, submit the report for pre-assessment of occupational-health harm to the competent public health authority. The preassessment report of occupation-health harm shall indicate the construction project's occupational-disease-inductive factor, its influence on the workplace and laborer health, and determine the type of harm and prevention measures against the occupational diseases.

The undertaking organization should carry out the assessment of the occupational-disease-prevention measures before the final acceptance of the construction project. No construction project shall be put into operation without having its occupational-disease-prevention facilities accepted by the public health authority upon the acceptance of the construction project.

\subsubsection{Qualifications and Certificates}

Qualifications and certificates, both for employees and equipments, are one of the most important aspects to control hazards. Under Production Safety Law of the People's Republic of China, the following qualifications and certificates are required:

Certificates for special operations: the special operation staff members of the production and business operation entities may not start to work at their positions until they have passed the special training regarding safe operations and obtained qualification certificates for special operations according to the relevant provisions of the state.

Qualifications: the persons-in-charge and the personnel for the administration of production safety of the entities that are engaged in the production, selling and storage of hazardous substances and the mines and construction entities shall not take their positions until they have passed the examinations of the administrative departments concerning the knowledge and management capacity of production safety.

The special equipment that concerns the safety of life or is rather dangerous, the container of hazardous substances or the transportation tool that any production and business operation entity uses shall, according to the relevant provisions of the state, be manufactured by the specialized production entities, and only after it has passed the detections and tests of the detecting and testing institutions that are equipped with the professional qualifications for which a certificate for safe use or a mark of safety has been obtained could it be put into use.

Any personal protective equipment provided to the laborer by the employer should comply with the applicable regulations of occupational disease prevention. The personal protective equipment should obtain three certificates (manufacturing license, product qualification cer- tificate, and safety appraisal permit). The production and business operation entity should provide PPE that meet the national occupational health standards to the workers and make supervisions to ensure their workers' correct use of such equipments.

\subsection{Interested Party}

Interested parties here refer to persons or groups concerned with the safety performance and activities of a production and business operation entity, such as contractors and lessees. Under Production Safety Law of the People's Republic of China, two or more production and business operations that conduct production and business operation activities within the same area and may endanger the production safety of each other shall enter into agreements concerning the administration of production safety so as to specify the duties and functions of each other in the administration of production safety as well as the safety measures to be taken, and shall arrange for full-time persons in charge of the administration of production safety to conduct safety inspections and coordination.

No production and business operation entity may contract or lease any project, site or equipment of production and business operation to any entity or person that does not have the conditions for safe production or have the corresponding qualifications.

In case a production and business operation project or site is contracted or leased to more than one entity, the production and business operation entity shall enter into special agreements with the contractor or leaseholder concerning the administration of production safety, or stipulate in the contracting agreements or leasehold contracts the duties and functions of each party in the administration of production safety. The production and business operation entity shall exercise unified coordination and administration over the contractors and leaseholders concerning the work of production safety.

\subsection{Accidents Reporting, Investigation and Disposition}

Production Safety Law of the People's Republic of China and the Regulations on the Reporting, Investigation and Disposition of Production Safety Accidents make provisions of procedures and responsibilities of incident reporting, investigation and disposition.

When a production safety accident occurs to a production and business operation entity, the relevant persons at the spot of the accident shall report to the persons-incharge of the entity immediately. The persons-in-charge of the entity shall, after receiving the report of accident, take effective measures immediately, organize rescues, and prevent the accident from deteriorating so as to re- 
duce the casualty of personnel and property losses. They shall, according to the Regulations on the Reporting, Investigation and Disposition of Production Safety Accidents, report truthfully to the departments responsible for the supervision and administration of production safety of the local place, and may not conceal anything or report deceitfully or delay the reports or ruin the spot of the accident on purpose or destroy relevant evidences.

The departments responsible for the supervision and administration of production safety shall, after receiving a report of accident, report the accident to the relevant authorities on higher levels according to Regulations on the Reporting, Investigation and Disposition of Production Safety Accidents. The persons-in-charge of the local people's governments concerned and the departments responsible for the supervision and administration of production safety shall, after receiving a report of production safety accident, hurry to the spot of the accident immediately to organize rescues.

The principle of being practical and realistic and the principle of respecting science shall be observed in the investigation and handling of accidents. The relevant people shall find out the accurate causes of the accidents in good time, sum up the lessons of the accidents, suggest measures for rectification and mending up, and give their opinions about how to deal with those who are responsible for the accidents.

\section{Introduction of OSH Legal System in Hong Kong}

\subsection{Supervisory Organization}

In Hong Kong, occupational safety and health issues are held responsible by the Labour Department, which is under the Department of Secretary for Labour and Welfare. The Labour Department has four key areas of work, namely Employment Services, Labour Relations, Safety and Health at Work, and Employee Rights and Benefits. The main services provided by the Labour Department are Occupational Safety Service and Occupational Health Service [4].

- Occupational Safety Officers enforce the Occupational Safety and Health Ordinance, the Factories and Industrial Undertakings Ordinance and the subsidiary Regulations through inspection of workplaces to ensure that the requirements on safety, health and welfare are complied with; carry out accident investigations and give advice to employers and employees on how to reduce existing workplace hazards; offer free advice to owners on the planning and layout of factories and workplaces, and in-plant/in-house safety programmes; provide support services to instill safety concepts to the public at large with a view to inculcating a safety culture among employers and em- ployees and securing their commitment to self-regulation to bring in a safety management approach in keeping with the Occupational Safety Charter; and operate the Occupational Safety and Health Training Centre which provides training for government and non-government personnel in occupational safety and health.

- The Occupational Health Service is made up of two Occupational Medicine Divisions and three Occupational Hygiene Divisions. Its main function is to prevent occupational diseases and to promote health at work. The major work of the divisions include: providing advisory services to the public on health and hygiene aspects of occupational health problems such as prevention of occupational diseases in workplaces; conducting field surveys to ensure that the requirements of health and hygiene at workplaces are complied with; enforcing legislation relating to occupational health and hygiene; investigating and providing treatment to suspected occupational disease cases; conducting sick leave clearance interview of employees with compensation claims; organizing exhibitions and delivering talks to promote the awareness of occupational health.

- The Boilers and Pressure Vessels Division is responsible for enforcing the Boilers and Pressure Vessels Ordinance (Cap. 56) to ensure the safe operation of boilers and pressure vessels. Its major work includes: registration of boilers and pressure vessels; carrying out spot checks on pressure equipment in work sites; conducting examinations and issuing certificate of competency to qualified candidates as competent persons for various types of boiler and steam receiver; monitoring the courses for the training of competent persons; promoting the safe use of boilers and pressure vessels by issuing Codes of Practice and through activities such as holding seminars and exhibitions; and providing technical support to the Fire Services Department in connection with pressure equipment covered by the Dangerous Goods Ordinance (Cap. 295).

On dealing with special subject areas, Committee on Occupational Safety and Health will be set up under the auspices of the Labour Advisory Board (LAB). It is a tripartite consultative body to advise on labour matters established to review the standards of occupational safety and health in Hong Kong; to advise on legislative proposals on occupational safety and health and review existing legislation; and to advise on the measures to be adopted by the Labour Department with a view to improving the existing system which enforces occupational safety and health legislation.

In addition, there are some related statutory boards such as the Employees' Compensation Insurance Levies 
Management Board, Occupational Deafness Compensation Board, Occupational Safety and Health Council, and Pneumoconiosis Compensation Fund Board.

Furthermore, Occupational Safety and Health Council (OSHC) is established as a related statutory board of Labour Department. The Chairman shall be appointed by the Chief Executive. The functions of OSHC are to foster greater awareness among the community; to promote the application of modern technology; to promote education and training; to disseminate technical knowledge; to develop strategies and formulate programmes; to provide consultancy services; and to encourage and facilitate cooperation and communication between the Government, employers, employees and relevant professional and academic bodies, in furtherance of the encouragement and promotion of higher standards of safety and health for people at work [5].

\subsection{The Legal System Framework on OSH}

Basic Law of the Hong Kong Special Administrative Region (HKSAR) was enacted by the National People's Congress in accordance with the Constitution of the People's Republic of China. It is akin to a mini-constitution for the HKSAR. All the systems and policies practiced in the HKSAR must be based on the provisions of the Basic Law. Those laws come from the legislature of SAR, the Legislative Council. The vast majority of statute laws in force in Hong Kong are made locally and contained in the Laws of Hong Kong [3]. This is called Ordinance. A great deal of legislations is made under delegated powers. This is called subsidiary legislation [13]. For example, Occupational Safety and Health Ordinance may delegate to the Commissioner for Labour the power to make regulations to deal with the details of the implementation of the legislative scheme [14]. Code of Practice (COP) has a special legal status, although failure to observe any guidance given in COP is not in itself an offence, the failure may be taken by a court in criminal proceedings as a relevant factor in determining whether or not a person has breached any of the provisions of a regulation to which the guidance relates. Thus, COP is a special level in the legal system of OSH in Hong Kong. Besides, the provisions and requirements in the Guidance Notes could be complied with of one's own accord, and it does not have the same important legal status as the above.

The legislation related to occupational safety and health is composed of three main parts as follows: Boilers and Pressure Vessels Ordinance, Chapter 56, which is composed of one subsidiary regulation and two orders; Factories and Industrial Undertakings Ordinance, Chapter 59, with 30 subsidiary legislations; and Occupational Safety and Health Ordinance, Chapter 509, which is composed of two subsidiary legislations.
The other legislations (contained in the Laws of Hong Kong) related to occupational safety and health include: Radiation Ordinance, Chapter 303; Employees Compensation Assistance Ordinance, Chapter 365; Occupational Safety and Health Council Ordinance, Chapter 398; Employees' Compensation Insurance Levies Ordinance, Chapter 411; Employees Retraining Ordinance, Chapter 423; Occupational Deafness (Compensation) Ordinance, Chapter 469; Builders' Lift and Tower Working Platforms (Safety) Ordinance, Chapter 470, etc.

The main list of Treaties in force and International Agreements applicable to the HKSAR related to occupational safety and health include: Working Environment (Air Pollution, Noise and Vibration) Convention, Geneva, 20.6.1977 (ILC No. 148); Radiation Protection Convention, Geneva, 22.6.1960 (ILC No. 115); Medical Examination of Young Persons (Underground Work) Convention, Geneva, 23.6.1965 (ILC No. 124), etc. [15].

Some international standards of OSH could be adopted if only that could satisfy the requirements of related legislations or with more advantages than that in Hong Kong, such as British Standards, Japanese Industrial Standards, American Military Standards, American Welding Society Standards and, International Labor Organization Standards, etc.

In general, the framework chart of legal system of occupational safety and health is shown in Figure 2.

\subsection{Major Laws on OSH}

Three major laws on OSH in Hong Kong were reviewed in this article: Occupational Safety and Health Ordinance, Occupational Safety and Health Regulation, Factories and Industrial Undertakings Ordinance and its subsidiary legislations.

\subsubsection{Occupational Safety and Health Ordinance}

The Occupational Safety and Health is basically an enabling ordinance setting out requirements in general terms. This ordinance covers almost all workplaces-places where employees work. In addition to factories, construction sites and catering establishments, other places such as offices, laboratories, shopping arcades, educational institutions also come under the ambit of the law. However, there are a few exceptions, such as an aircraft or vessel in a public place; the place occupied by the driver of a land transport vehicle when it is in a public place (but other employees working in the vehicle are covered); domestic premises at which only domestic servants are employed; and places where only self-employed persons work.

Under this ordinance, everyone has a role to play in creating a safe and healthy workplace. Employers should contribute to safety and health in their workplaces by providing and maintaining plant and work systems that do not endanger safety or health; making arrangement for 


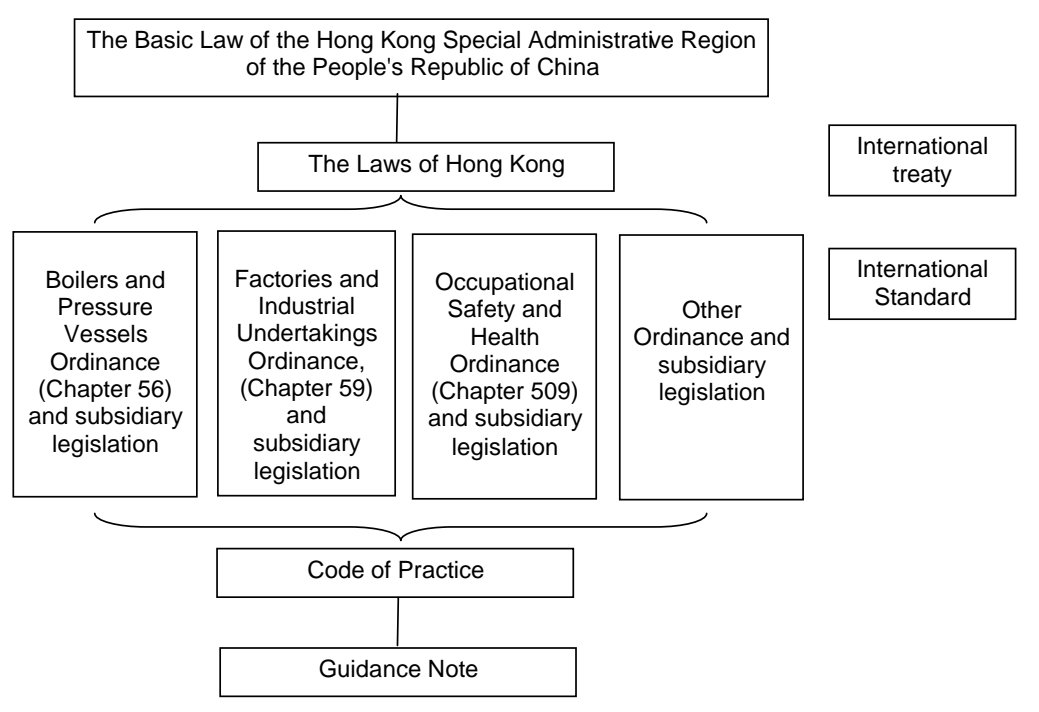

Figure 2. Framework chart of legal system of OSH in Hong Kong.

ensuring safety and health in connection with the use, handling, storage or transport of plant or substances; providing all necessary information, instruction, training, and supervision for ensuring safety and health; providing and maintaining safe access to and egress from the workplaces; and providing and maintaining a safe and healthy work environment. Occupiers of premises should take responsibility for ensuring that the premises; the means of access to and egress from the premises; and any plant or substance kept at the premises are safe and without risks to health to any person working in the premises, even if they do not directly employ that person in the premises. Employees should also contribute to safety and health in the workplaces by taking care of the safety and health of persons at the workplace; and using any equipment or following any system or work practices provided by their employers.

The Commissioner for Labour is empowered to issue improvement notices and suspension notices against activity of workplace which may create an imminent hazard to the employees. Failure to comply with the notices constitutes an offence punishable by a fine of $\mathrm{HK}$ $\$ 200,000$ and HK \$500,000 respectively and imprisonment of up to 12 months.

\subsubsection{Occupational Safety and Health Regulation}

The Occupational Safety and Health Regulation, made under the above ordinance, sets out some basic requirements for accident prevention, fire precaution, workplace environment control, hygiene at workplaces, first aid, as well as what employers and employees are expected to do in manual handling operations.

The main provisions of the Regulation are:

- To prevent accidents by ensuring that the plant is properly designed, constructed and maintained; all dan- gerous parts are effectively guarded; and all dangerous areas are securely fenced.

- To prevent fire by providing illuminated "EXIT" signs in all exits and clear directions to them; keeping all means of escape in a safe condition and free from obstruction; making sure that all exit doors can easily be opened from inside the workplace or are unlocked; and providing suitable and adequate fire safety measures.

- To provide a safe and healthy work environment by keeping the workplace clean and ensuring that it is adequately lit and ventilated; and provide adequate drainage.

- To ensure hygiene by providing adequate lavatory and washing facilities, as well as adequate supply of drinking water.

- To provide first aid by keeping adequate first aid facilities in the premises and appointing designated employees to look after them.

- To ensure safe manual handling operations by assessing and reviewing risks to the safety and health of employees who undertake manual handling operations; and providing proper training and other necessary protective measures for employees who undertake manual handling operations.

\subsubsection{Factories and Industrial Undertakings Ordinance and Its Subsidiary Legislation}

The Factories and Industrial Undertakings Ordinance provides for the safety and health protection to workers in the industrial sector. This ordinance applies to Industrial undertakings, i.e. factories, construction sites, catering establishments, cargo and container handling undertakings, repair workshops and other industrial workplaces. 
This ordinance imposes general duties on proprietors and persons employed at industrial undertakings to ensure safety and health at work. Every proprietor should take care of the safety and health at work of all persons employed by him at an industrial undertaking by providing and maintaining plant and work systems that do not endanger safety or health; making arrangement for ensuring safety and health in connection with the use, handling, storage or transport of plant or substances; providing all necessary information, instructions, training, and supervision for ensuring safety and health; providing and maintaining safe access to and egress from the workplaces; and providing and maintaining a safe and healthy work environment. Every person employed at an industrial undertaking should also contribute to safety and health at work by taking care of the safety and health of himself and other persons at the workplace; and using any equipment or following any system or work practices provided by the proprietor.

With respect to notification of workplaces, the ordinance provides that: a person having the management and control of a factory or other industrial establishment (but excluding a construction site) should notify the Commissioner for Labour in a prescribed form (obtainable from various district offices of the Occupational Safety Operations Division) before commencement of operation. Any subsequent changes in the particulars of the workplace, e.g. its name, location or the industrial processes, should also be notified to the Commissioner for Labour in a prescribed form (obtainable from various district offices of the Occupational Safety Operations Division). A contractor should notify the Commissioner in writing within 7 days after commencement of any construction work under the Construction Sites (Safety) Regulations.

Under the Factories and Industrial Undertakings Ordinance, there are 30 sets of subsidiary regulations covering various aspects of hazardous work activities in factories, building and engineering construction sites, catering establishments, cargo and container handling undertakings and other industrial workplaces. The subsidiary regulations prescribe detailed safety and health standards on work situations, plant and machinery, processes and substances. The subsidiary regulations are shown as follows: Construction Sites (Safety) Regulations, Factories and Industrial Undertakings Regulations, Quarries (Safety) Regulations, Factories and Industrial Undertakings (Abrasive Wheels) Regulations (or Abrasive Wheels Regulations), Asbestos Regulation, Blasting by Abrasives Special Regulations, Carcinogenic Substances Regulations, Cargo and Container Handling Regulations, CartridgeOperated Fixing Tools Regulations, Confined Spaces Regulation, Dangerous Substances Regulations, Dry Batteries Regulations, Electricity Regulations, Electrolytic
Chromium Process Regulations, Fire Precautions in Notifiable Workplaces Regulations, First Aid in Notifiable Workplaces Regulations, Gas Welding and Flame Cutting Regulation, Goods Lifts Regulations, Guarding and Operation of Machinery Regulations, Lifting Appliances and Lifting Gear Regulations, Loadshifting Machinery Regulation, Noise at Work Regulation, Notification of Occupational Diseases Regulations, Protection of Eyes Regulations, Safety Officers and Safety Supervisors Regulations, Spraying of Flammable Liquids Regulations, Suspended Working Platforms Regulation, Woodworking Machinery Regulations, Work in Compressed Air Regulations, and Safety Management Regulation.

\section{Comparison of Characteristics on the OSH Legal System}

There are many similar points of general management of $\mathrm{OSH}$ between Hong Kong and Mainland China, such as the management of occupational diseases, safety production, dangerous goods, the boilers and pressure vessels, etc.

\subsection{Characteristics of the Legal System in Mainland China}

First of all, the production operation entities and organizations and key personnel in charge are the main responsible body. Under the legal system in Mainland China, it includes the production and business operation entities and person in charge, a department and its officers responsible for the supervision and administration of production safety, local people's government or a relevant department of a people's government at or above the county level and the directly responsible persons in charge and other directly liable persons, institution and the directly responsible persons in charge and other directly liable persons that undertakes the work of safety appraisal, certification, detection and test, the workers, etc. Any entity or individual that violates any provision of relevant laws, causes serious consequences shall assume the civil liability according to law. Where a violation of any provision of relevant laws constitutes a crime, the offender shall be pursued for criminal liability.

The operating unit of production or government institution, not individuals, is more regarded as the subject by laws in Mainland China. Enterprise's legal liability is usually undertaken by the person in charge, and the safety personnel in enterprises. Persons, if not violates the law, would only be punished by the internal system of enterprises.

Secondly, with respect to control of hazards, it is still focused on the control of the significant risk by legal means. This includes the system of creating archivist files for major hazards, the system of production safety 
license in key industries (entities that produce, manage or store hazardous substances and fireworks and civilian explosives manufacturers as well as the mining and construction building entities), safety assessment and occupational health assessment of construction projects, etc. Thus, the OSH management in Mainland China is still in the stage of development.

In addition, the legal status of emergency management was highlighted. After the outbreak of Severe Acute Respiratory Syndrome (SARS), a respiratory infection that occurred in a number of regions in 2003, Mainland China started to strengthen the emergency management and legislative work. The National Emergency Response Program for Public Incidents was issued in 2006, and the Emergency Response Law of the People's Republic of China was promulgated in 2007. This law promotes the emergency management to the legal status to manage. This symbolizes the preliminary formation of the China emergency laws and regulations frame. An emergency incident as mentioned in this Law refers to one of the following kinds of events: a natural disaster, accidental disaster, public health incident or social safety incident. Such emergency response activities as prevention and preparedness, surveillance and warning, response operations and rescue, and post-emergency response rehabilitation and reconstruction are provided in this Law.

Lastly, a clear and systematic level of standard system is a distinct characteristic of the legal system in Mainland China. It includes national standards, industrial standards and local standards, and according to the execution, the standards are divided into mandatory standards and recommended standards. This system is suitable for the characteristics of Mainland China with the broad clime and numerous industries.

\subsection{Characteristics of the Legal System in Hong Kong}

The characteristics of the legal system of occupational safety and health in Hong Kong are summarized as follows:

1) Clear definition of duties. The annotation of the meaning governed by the Laws of Hong Kong is that "begins with individuals, everybody has the right to seek to protect to a court. Ruling by law regards individual as the starting point, then contain the whole society" [16]. Thus, all duties were defined on person under the legislation, for instance, the duties delegate to the following persons by related legislation:

- The Commissioner for Labour: Occupational Safety and Health Ordinance may delegate to the Commissioner for Labour the power to make regulations to deal with the details of the implementation of the legislative scheme.

- Safety Officer: duties of a safety officer include ad- vising the proprietor on measures to be taken in the interest of the safety and health of persons employed in the industrial undertaking and, with the approval of the proprietor, implementing such measures; inspecting the industrial undertaking, reporting the findings of any inspection, etc. [17].

- Registered Engineers: for instance, a registered lift engineer or registered escalator engineer shall in carrying out any lift works or escalator works, as the case may be ensure that the lift works or escalator works comply with the requirements of related ordinance; and examine the lifts or escalators in question and test the safety equipment provided therefore and examine and test any lifts or escalators to which major alterations have been made, in accordance with related ordinance.

- Registered Contractor and Registered Examiner: a registered contractor and registered examiner in carrying out his responsibilities shall ensure that the safety and design requirements are complied with.

- Medical Practitioner: if a medical practitioner finds or suspects that the employee or former employee is or was suffering from an occupational disease, the practitioner must notify the finding or suspicion to the Commissioner.

It is more regarded the operating unit of production or government institution, not individuals, as the subject by laws in Mainland China, enterprise's legal liability is usually undertaken by the person in charge, and the safety personnel in enterprises, if not offend against the crime, only were punished by the internal system of enterprises.

2) Formal characteristic of the law: it often contains long title, short title, interpretation, application, powers and duties of related person, general requirements, offences and penalties, appeal to court, regulations, schedules, etc. In addition, it will set up committees in some regulations, and prescribe its duties. The descriptions are more detailed than the laws of Mainland China, and there is unattached title of each item, which is revised and labeled severally.

3) Writing approach of the legislation. There are two main approaches to writing legislations: prescriptive approach and performance-based approach. Detailed technical standards are prescribed in the legislation written by prescriptive approach. For instance, under Factories and Industrial Undertakings Ordinance, the landing place or test place or rest platform shall be provided with a guard-rail or guard-rails of adequate strength to a height of between $900 \mathrm{~mm}$ and $1150 \mathrm{~mm}$. Performance-based approach is widely used in recent years and will be the main development trend in future. These kinds of legislation do not prescribe detailed standards, but to make objectives only. This is due to the rapid development of 
science and technology that results in the prescriptive approach cannot be applicable to the equipments, techniques and materials used in modern industrial undertakings.

4) Offences and penalties. The clause about declaring guilty is described carefully. For instance, an occupational safety officer may require a responsible person to exhibit notice (such as any plant or substance installed or kept at the workplace) in workplace. A person who intentionally or recklessly interferes with, or misuses, an article provided at a workplace in the interests of the safety or health of employees employed at the workplace commits an offence and is liable on conviction to a fine at level 5 .

5) The provisions as to procedures of examination: there are direct relationships between employer and registered examiner or engineer, but not the government agency. For instance, the owner of every lift shall, at intervals not exceeding 12 months, cause the lift to be thoroughly examined by a registered lift engineer in order to determine whether the lift and all machinery and equipment connected therewith is in safe working order and, without prejudice to the generality of the foregoing, and make registration and report.

6) The canonical requirements of forms. The provisions of uniform forms were required under some regulations, such as Form of Application for Registration, Notice of Occupational Disease, etc.

\subsection{Recommendations to Improve OSH}

Some areas are proposed to improve OSH both in Mainland China and Hong Kong.

For Mainland China, the concept of systemic management of OSH should be introduced. There are legislations on many areas of OSH management in Mainland China, such as management of hazard, special equipment, safety assessment and accident reports. But these are under isolated management. In contrast this, under Safety Management Regulation in Hong Kong, a safety management system consisting of some or all of the fourteen elements must be developed, implemented and maintained by a proprietor or contractor. This is a systemic safety management system to promote the systematization of OSH management in factories and industrial undertakings by regulations. Meanwhile, the national standard Occupational Health and Safety Management Systems-Specifications (GB/T 28001) is a voluntary standard, and is lack of constraint. A systematic framework of OSH management by laws should be established to improve the areas of OSH which is incomplete or unfounded.

The second important area for improvement in Mainland China is to apply normative schedules and forms in laws and regulations, such as reports, forms and records. For instance, if the form of an accident report is normative, it will benefit both the accident investigation for the organization where the accident took place and the accident classification, statistic and analysis for government agencies.

Thirdly, full display of the specialists' professional ability is an important area to improve. The certified safety engineer system was set up in 2004 in Mainland China. The management experience of registered safety officers in Hong Kong could be used for reference during the process of identifying duties and right of certified safety engineer. The certified safety engineer and persons with relevant safety techniques, such as checkers, auditors and trainers, should be empowered clear and great duties and rights with the aim of promoting them who display the specialized ability well in the Industrial enterprise and other organizations.

On the other hand, for Hong Kong, a series of special regulations need to be set up. Emergency management is one of the areas to improve. There is no categorized management of emergency, such as natural disaster, accidental disaster or public health incident, in current legal system in Hong Kong. In that sense, the emergency management legal framework in Mainland China can be implemented and used as reference in order to improve the emergency management in Hong Kong.

In addition, it is proposed to improve the classification of dangerous accidents. There are eight dangerous occurrences listed in Schedule 1, Occupational Safety and Health Ordinance in Hong Kong, which does not mention such dangerous occurrences as burns, floods, drowns, poisoning and asphyxia, etc. This is in contrast to six classes of hazards identified in the standards Classification and Code for the Hazardous and Harmful Factors in Production process (GB/T 13861-92), and 20 classes of accidents classified under the Classification Standard for the Casualty Accidents of Enterprise Staff and Workers (GB 6441-86) in Mainland China. Providing more detailed standards as guidance to hazard identification and control is a critical reform area.

Lastly, a gradual restriction system for strengthening the management of contractor and a broader scope of interest parties should be improved in Mainland China and Hong Kong respectively. Special OSH provisions are identified for the contractors and sub-contractors in Hong Kong because the construction industry is the most dangerous industry. This means in case the contractor further sub-contracts all or part of his work to other sub-contractors, the contractor should ensure that the sub-contractors are fully aware of the safety policy and the safety rules. This is the gradual restriction system that could be used as reference in Mainland China. On the contrary, a broader scope of interest parties needs to be identified and managed in Hong Kong. There are unclear regula- 
tions relevant to many other interest parties, except contractors, such as material and equipment providers, transporters on OSH. Such provisions are prescribed in Mainland China, for instance, for two or more production and business operations that conduct production and business operation activities, including contractors, material and equipment providers, etc., within the same area and may endanger the production safety of each other shall enter into agreements concerning the administration of production safety so as to specify the duties and functions of each other in the administration of production safety as well as the safety measures to be taken, and shall arrange for full-time persons in charge of the administration of production safety to conduct safety inspections and coordination. Therefore, it is proposed that a broader scope of management of interest parties should be identified by legislation in Hong Kong.

\section{Conclusions and Challenges}

Except for the similar areas, such as on the management of occupational health, safety production, fire safety, dangerous goods, the boilers and pressure vessels, etc., there are several differences in the legislation system on OSH between Mainland China and Hong Kong. As a consequence, there are differences in the requirements on OSH management, both in terms of supervisory mechanism and characteristics.

It is suggested that an OSH management system which is applicable to various types of organizations should be established under the legal framework to promote the comprehensive development of OSH and to protect the occupational health and safety of every member in the society. Every organization should establish a system of OSH management framework to protect all persons' health and safety relevant to the activities of the organizations. At present, both in Mainland China and in Hong Kong, the relevant provisions of OSH by legal system are focusing on the major industrial enterprises, and there is no related restraint to other types of organizations. However, with the development of technology and society, except for the factories and industrial enterprises which are applying new technologies, organizations such as government agencies, will be involved in the new OSH issues, such as work under stress, occupational hazards brought by computers, and other occupational hazards.

Furthermore, inherent safety is a concept that the safety process has a low level of danger even if things go wrong. It is used in contrast to safety systems where a high degree of hazard is controlled by protective systems. As perfect safety cannot be achieved, common practice is to talk about inherently safer design. "An inherently safer design is one that avoids hazards instead of controlling them" [18].
Inherent safety has been recognized as a desirable principle by a number of national authorities, including the US Nuclear Regulatory Commission (NRC) [19,20] and the UK Health and Safety Executive (HSE). In assessing COMAH sites, the HSE states that "major accident hazards should be avoided or reduced at source through the application of principles of inherent safety" [21]. The European Commission in its Guidance Document on the Seveso II Directive states that "hazards should be possibly avoided or reduced at source through the application of inherently safe practices" [22]. In the USA, Contra Costa County requires chemical plants and petroleum refineries to implement inherent safety reviews and make changes based on these reviews [23]. Thus, how to promote the development of "inherent safety and health" through the impact of legal system is a new challenge for both Mainland and Hong Kong.

\section{REFERENCES}

[1] State Administration of Work Safety, "Diagram of the Organization," 2008.

http://www.chinasafety.gov.cn/aj-zuzhijigou.htm

[2] General Administration of Quality Supervision, "Inspection and Quarantine of the People's Republic of China," 2009. http://tzsbaqjcj.aqsiq.gov.cn/

[3] Ministry of Health of the People's Republic of China, "Function of the Organization," 2008.

http://www.moh.gov.cn/publicfiles/business/htmlfiles/zw gkzt/pjggk/200804/621.htm

[4] Department of Justice, “The Laws of Hong Kong,” Hong Kong Special Administrative Region, 1997.

[5] Department of Justice, "Legal System in Hong Kong," Information Based on the Departmental Publication, Hong Kong Government, 2008.

[6] Standardization Administration of the People's Republic of China, "Personal Protective Equipment Terminology," GB/T 12903-91, China, 1991.

[7] Department of Justice, "The Laws of Hong Kong," Occupational Safety and Health Ordinance Cap. 509, Hong Kong Special Administrative Region, 1997.

[8] Standing Committee of the National People's Congress, "Law of the People's Republic of China on the Prevention and Treatment of Occupational Diseases,” 2001. http://www.lawinfochina.com/law/display.asp?id=2089

[9] Standing Committee of the National People's Congress, "Production Safety Law of the People's Republic of China," 2002.

http://www.lawinfochina.com/law/display.asp?id=2387

[10] Standing Committee of the National People's Congress, "Fire Protection Law of the People's Republic of China," 2008.

http://www.lawinfochina.com/law/display.asp?id=2387

[11] State Council, "Work-related Injury Insurance Regulations," Order of the State Council (No. 375), People's Republic of China, 2004. 
[12] State Council, "The Regulations on the Reporting, Investigation and Disposition of Production Safety Accidents," Order of the State Council (No. 493), People's Republic of China, 2007.

[13] Department of Justice, "List of Treaties in Force and Applicable to the Hong Kong Special Administrative Region,” 2009.

http://www.legislation.gov.hk/interlaw.htm\#International \%20Labour\%20Conventions

[14] Labour Department, “Access to Information,” Hong Kong Government, 2009. http://www.labour.gov.hk/eng/home/

[15] Department of Justice, “The Laws of Hong Kong,” Occupational Safety and Health Ordinance Cap. 398, Hong Kong Special Administrative Region, 1997.

[16] Department of Justice, "Legal System in Hong Kong," Information Based on the Departmental Publication, Hong Kong Government, 2004.

[17] Department of Justice, “The Laws of Hong Kong,” Factories and Industrial Undertakings (Safety Officers and Safety Supervisors) Regulations Cap. 59Z, Hong Kong
Special Administrative Region, 2002.

[18] A. M. Heikkilä, "Inherent Safety in Process Plant Design: An Index-Based Approach,” Technical Research Centre of Finland, VTT Publications 384, 1999.

[19] National Archives and Records Administration, 10 CFR Part 50, "Regulation of Nuclear Power Plants: Draft Statement of Policy,” Federal Register, 73(91), National Archives and Records Administration, USA, 2008.

[20] Health and Safety Executive, "The Safety Report Assessment Manual,” Health and Safety Executive, UK, 2008.

[21] G. A. Papadakis and A. Amendola, Eds., "Guidance on the Preparation of a Safety Report to Meet the Requirements of Council Directive 96/82/EC (Seveso II)," European Commission-Joint Research Centre, Institute for Systems Informatics and Safety, Major Accident Hazards Bureau, 1997.

[22] R. Sawyer, C. N. Cheung, M. Dossey, D. Nixon, H. Amin and N. Alaniz, "Regulating Inherent Safety," Center for Chemical Process Safety (CCPS) 22nd International Conference, American Institute of Chemical Engineers (AIChE), New York, 2007. 